\title{
The Perception Gap of Nuclear Energy between Public and Experts after the Fukushima Nuclear Power Plants'Accident
}

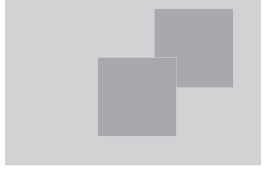

The University of Tokyo, Hiroshi Kimura

Since 2007, a special committee established by the Atomic Energy Society of Japan (AESJ) has been conducting a series of surveys of Greater Tokyo residents and AESJ members regarding their attitudes toward nuclear energy. The committee was assigned the task of developing and updating a database on media coverage and public opinion with respect to nuclear energy. This commentary refers to the survey results to explain changes in the perception gap between these two target groups before and after the Fukushima Daiichi nuclear accident.

\section{Introduction}

The 2011 Tohoku earthquake (also known as the Great East Japan earthquake) and tsunami that struck on March 11 affected nuclear power plants operated by the Japan Atomic Power Company (Tokai Daini), the Tokyo Electric Power Company (e.g., Fukushima Daiichi and Fukushima Daini), and the Tohoku Electric Power Company (Onagawa and Higashidori), as well as the Rokkasho Nuclear Fuel Reprocessing Facility operated by Japan Nuclear Fuel Limited. The accident that occurred at the Fukushima Daiichi Nuclear Power Station (hereinafter referred to as the "Fukushima nuclear accident") caused extensive damage, and this has most likely had a substantial impact on people's attitudes toward nuclear energy. The accident has presumably led to radical changes in the perception of nuclear experts, as well.

Since 2007, the Special Committee on Mass Media, which was established by the Atomic Energy Society of Japan (AESJ), has been conducting a series of surveys on Greater Tokyo residents and AESJ members regarding their attitudes toward nuclear energy. The committee has been assigned the task of developing and updating a database on media coverage and public opinion with respect to nuclear energy. The survey was also conducted in January 2012, about a year after the Fukushima nuclear accident. This commentary refers to the survey results to explain changes in the perception gap between these two target groups before and after the Fukushima Daiichi nuclear accident. After presenting what Greater Tokyo residents expect from the AESJ, the commentary discusses what roles the AESJ should play with due consideration given to the future relationship between the nuclear power and society as a whole.

DOI : 10.15669/fukushimainsights.Vol.3.13

(C) 2021 Atomic Energy Society of Japan. All rights reserved.

Originally published in Journal of the Atomic Energy Society of Japan (ISSN 1882-2606), Vol. 54, No. 9, p. 606-610 (2012)

in Japanese. (Japanese version accepted: July 8, 2012) 


\section{Surveys}

Numerous surveys and studies have already been conducted to assess people's perceptions of nuclear energy quantitatively with a view to discussing the relationship between society and nuclear energy. These surveys and studies have identified the benefits, anxiety concerning nuclear power, and trust in electric power companies, the government, and workers at nuclear facilities as the key psychological factors ${ }^{1}$. The perception gap between experts and non-experts is also an important issue when discussing whether nuclear energy is accepted or rejected by society.

Accordingly, in order to track changes in the perception gap between experts and nonexperts over time, the Special Committee on Mass Media has been conducting a series of questionnaire surveys to measure these psychological factors among non-expert residents of the Greater Tokyo Area and experts affiliated with the AESJ. The first questionnaire survey on energy and nuclear power was conducted in January 2007. To date, these surveys have been conducted five times on Greater Tokyo residents and six times on AESJ members. Table 1 summarizes the surveys conducted so far.

This commentary refers to surveys conducted on the two target groups at similar times from December 2008 onward (the second to fifth surveys for Greater Tokyo residents and the third to sixth surveys for AESJ members) to present information on the perception gap between them ${ }^{2}$.

\section{Perceptions of Nuclear Energy}

This section presents information on how perceptions of nuclear energy before and after the Fukushima nuclear accident have changed among the two target groups (i.e., Greater Tokyo residents and AESJ members). The relative degree of interest in nuclear energy compared to other areas of concern is shown before two psychological factors that are

Table 1 Summary of surveys conducted

\begin{tabular}{|c|c|c|}
\hline & $\begin{array}{l}\text { Surveys of Greater } \\
\text { Tokyo residents }\end{array}$ & $\begin{array}{c}\text { Surveys of AESJ } \\
\text { members }\end{array}$ \\
\hline $\begin{array}{l}\text { Target } \\
\text { group }\end{array}$ & $\begin{array}{l}\text { Residents within } 30 \mathrm{~km} \\
\text { of the city center }\end{array}$ & AESJ members \\
\hline Method & $\begin{array}{l}\text { Questionnaires collected } \\
\text { later from respondents } \\
\text { assigned based on quota } \\
\text { sampling }\end{array}$ & $\begin{array}{l}\text { Survey sheets mailed to } \\
1,400 \text { randomly chosen } \\
\text { members }\end{array}$ \\
\hline $\begin{array}{l}\text { Survey } \\
\text { period }\end{array}$ & $\begin{array}{ll}\text { Round 1 } & \text { May 2007 } \\
\text { Round 2 } & \text { Dec. 2008 } \\
\text { Round 3 } & \text { Jan. 2010 } \\
\text { Round 4 } & \text { Jan. 2011 } \\
\text { Round 5 } & \text { Jan. 2012 }\end{array}$ & $\begin{array}{ll}\text { Round 1 } & \text { Jan. 2007 } \\
\text { Round 2 } & \text { Jan. 2008 } \\
\text { Round 3 } & \text { Dec. 2008 } \\
\text { Round 4 } & \text { Jan. 2010 } \\
\text { Round 5 } & \text { Jan. 2011 } \\
\text { Round 6 } & \text { Jan. 2012 } \\
\end{array}$ \\
\hline $\begin{array}{l}\text { Responses } \\
\text { (Response } \\
\text { rate) }\end{array}$ & 500 & $\begin{array}{ll}\text { Round 1 } & 559(39.9 \%) \\
\text { Round 2 } & 591(42.2 \%) \\
\text { Round 3 } & 611(43.6 \%) \\
\text { Round 4 } & 625(44.6 \%) \\
\text { Round 5 } & 624(44.6 \%) \\
\text { Round 6 } & 611(43.6 \%)\end{array}$ \\
\hline
\end{tabular}


considered influential in any assessment of the social acceptance of nuclear energy are discussed: "Use and benefits of nuclear power" and "Reassurance, safety, and trust."

\section{Interest in General Social Issues}

Figure 1 shows the varying degrees of interest in general social issues according to the survey conducted on the two target groups in January 2012.

In January 2012, the Greater Tokyo residents who were surveyed tended to be interested in the following issues: "Natural disasters," "Political and economic issues," "Diseases," "Accidents at nuclear facilities," and "Global warming and other environmental issues." Due to space limitations, the results of surveys conducted on non-experts before the Fukushima nuclear accident cannot be presented in this commentary, but interest in "Accidents at nuclear facilities" heightened after the accident. Respondents expressed even greater interested in "Natural disasters," an issue that has always been their major concern. Similarly, they became notably more interested in "Radioactive waste" and "Nuclear energy."

Meanwhile, AESJ members tended to be interested in issues such as the following: "Nuclear energy," "Resources and energy," "Science and technology," "Political and economic issues," "Accidents at nuclear facilities," "Global warming and other environmental issues," and "Radioactive waste." Compared to the results for surveys conducted before the Fukushima nuclear accident, there was a rise in interest with respect to "Political and economic issues," "Accidents at nuclear facilities," and "Natural disasters."

Somewhat similar trends can be noted for the two target groups before and after the Fukushima nuclear accident. The likely causes for this are the devastation caused by the 2011

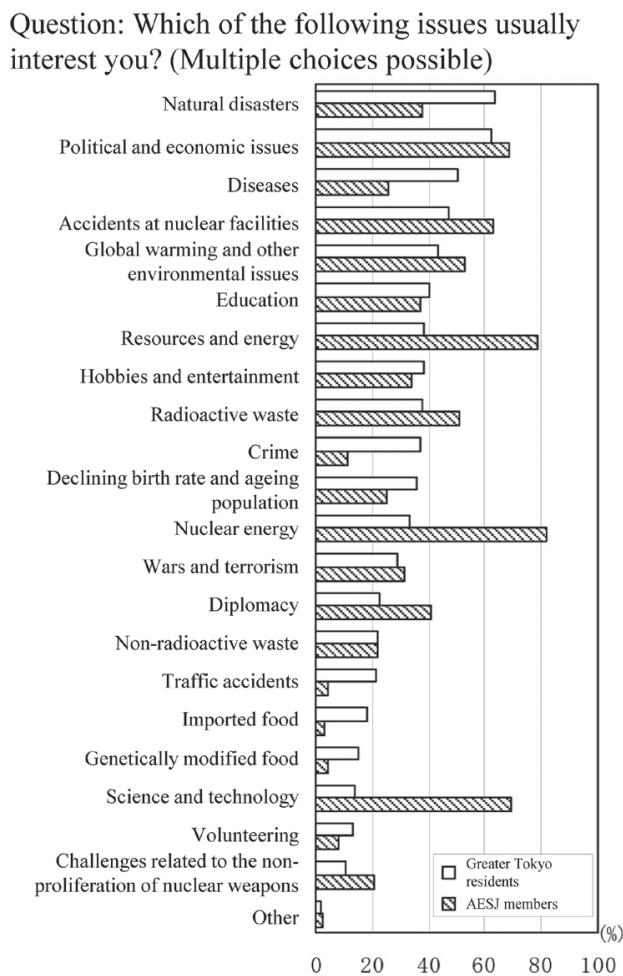

Figure 1 Interest in general social issues (January 2012) 
Tohoku earthquake and tsunami, the subsequent Fukushima nuclear accident, and the political turbulence associated with these events.

A closer examination of the survey results for January 2012 indicates that, compared to AESJ members, Greater Tokyo residents tend to be less interested in "Nuclear energy," "Science and technology," and "Resources and energy." In contrast, AESJ members tend to be less interested in issues related to personal risk, such as "Diseases," "Crime," and "Traffic accidents." This tendency is probably attributable to the different social realities that they face.

\section{Use and Benefits of Nuclear Power}

Figure 2 compares the opinions that Greater Tokyo residents and AESJ members held with respect to the use of nuclear power before and after the Fukushima nuclear accident. Similarly, Figure 3 compares the opinions of these target groups on possible alternatives to nuclear power, while Figure 4 compares their opinions on the energy sources that they believe will account for the greatest share of power generation 20 years later from now. These results carry the implications described below.

First, the opinion of Greater Tokyo residents is summarized. A comparison of the surveys conducted before and after the Fukushima nuclear accident demonstrates that the number of Greater Tokyo residents who selected "Definitely continue using nuclear power" fell and that notably more of them chose "Definitely abandon nuclear power." However, many of them were undecided (in favor of continuing to use nuclear power: $20.6 \%$; in favor of abandoning nuclear power: 48.8\%; and no opinion: 30.4\%). Furthermore, as shown in Figure 3, more people have come to recognize the alternatives to nuclear power. The perceived benefits of

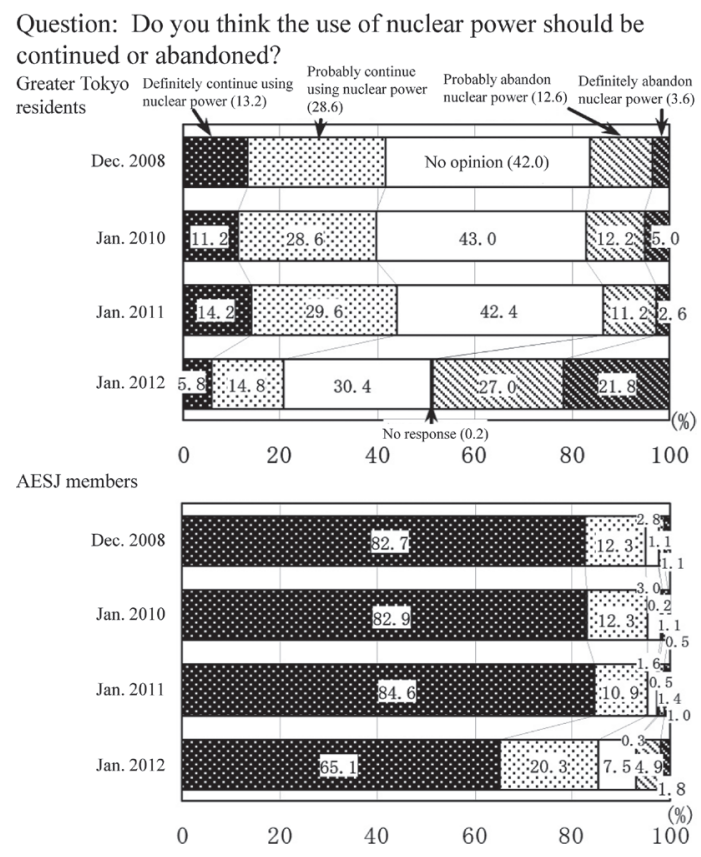

Figure 2 Use of nuclear power 


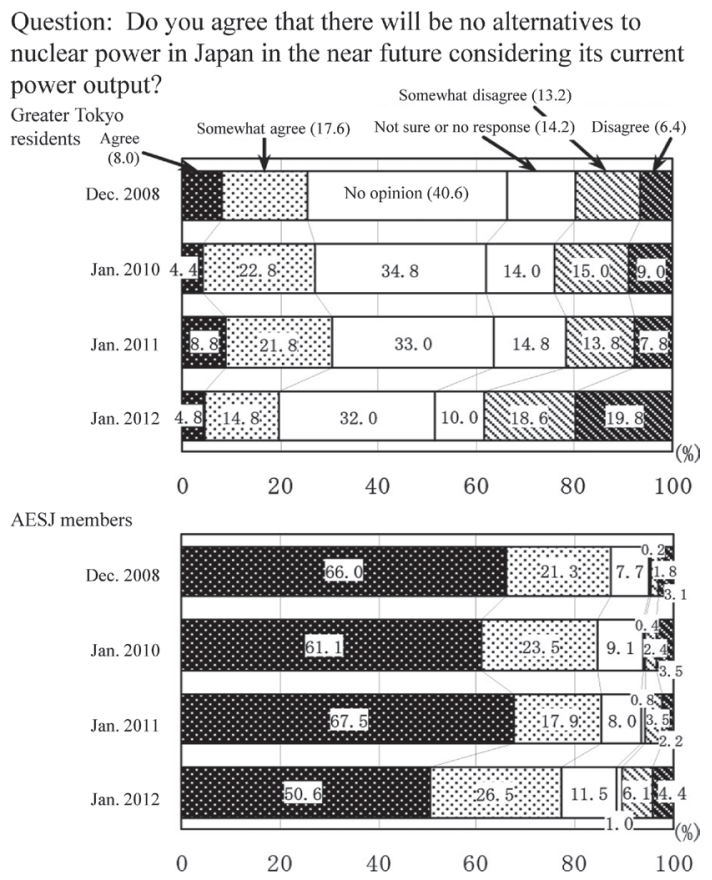

Figure 3 Possible alternatives to nuclear power

Question: In 20 years from now, which mode of power generation will help Japan to secure the highest power output?

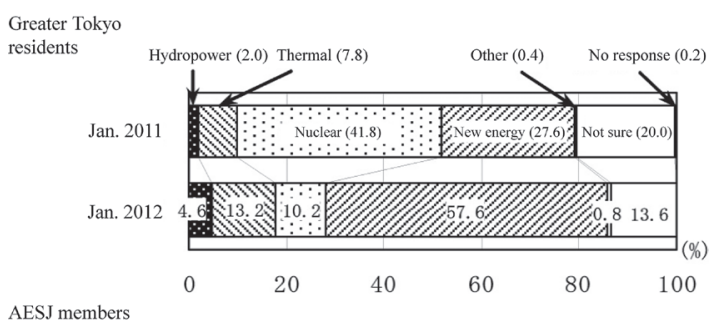

AESJ members

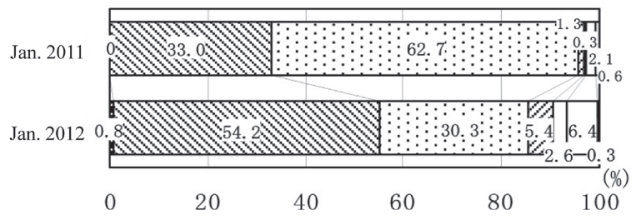

Figure 4 Mode of power generation with the highest output expected in 20 years later

* This question was added to the surveys conducted in January 2011 onward.

nuclear power in terms of issues such as curbing global warming and pursuing nuclear reprocessing to secure more energy have decreased.

In a related vein, greater expectations concerning new energy sources, such as solar, wind, and biomass energy, were observed in the survey results from January 2012. In fact, more than half of the respondents believed that a new source of energy would produce the highest power output in 20 years later $(57.6 \%)$.

Meanwhile, the majority of AESJ members are in favor of continuing to use nuclear power 
even after the accident. They also recognize the benefits of nuclear power. However, this share has decreased from previous levels. Interestingly, the shares of experts who are ambivalent or inclined to abandon nuclear energy have increased slightly to $7.5 \%$ and $6.7 \%$, respectively.

After the Fukushima nuclear accident, slightly fewer experts were convinced that there is no alternative to nuclear power. In earlier surveys, the majority of experts expected nuclear energy to produce the highest power output in 20 years later. In the survey conducted in January 2012, however, many more respondents believed that thermal power generation would do so instead.

A gap had already existed between the two target groups with respect to those in favor of continuing the use of nuclear power and those inclined to abandon it, but this gap seems to have widened since the Fukushima nuclear accident.

For both of the target groups in the survey conducted in January 2012, fewer respondents believed that nuclear energy would produce the highest power output in 20 years later. Nonetheless, these groups had a wide perception gap regarding possible alternatives to nuclear energy and the most significant source of energy in the future. Greater Tokyo residents had high expectations for new sources of energy, whereas AESJ members believed that thermal power generation would be the most viable alternative to nuclear energy.

\section{Reassurance, Safety and Trust}

Figure 5 shows the changing proportions of the two target groups in terms of whether they felt at ease or uneasy about nuclear power before and after the Fukushima nuclear accident.

Even before the accident, about half of Greater Tokyo residents felt uneasy about the use of nuclear energy. That proportion increased to $70.8 \%$ in January 2012 as the accident apparently

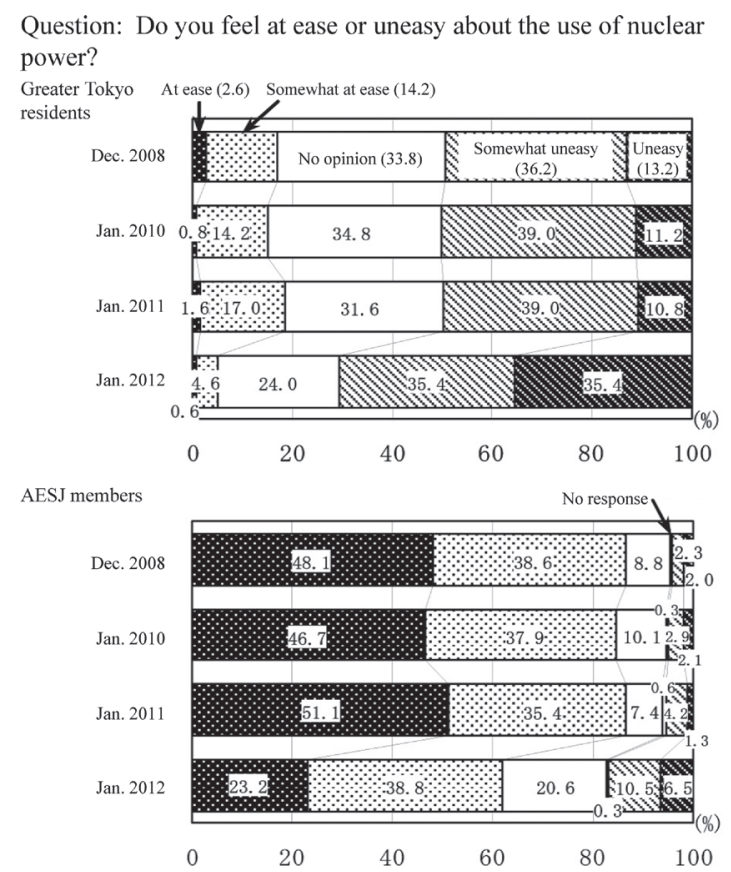

Figure 5 Sense of ease or unease about the use of nuclear power 
alarmed people. Although specific questions related to safety are not covered in this figure, many residents already believed that nuclear power plants had become less safe after their extended operation and that they were vulnerable to earthquakes. According to the results of the survey conducted in 2012, even more residents believe this now. Residents who had been ambivalent about safety and hazards in response to specific survey questions before the Fukushima nuclear accident seem to have concluded that nuclear energy is dangerous now.

Compared to the results of surveys conducted prior to the Fukushima nuclear accident, the share of AESJ members who felt at ease about nuclear power dropped to about $60 \%$. In earlier surveys, the majority of experts disagreed with the idea that the safety of a nuclear power plant decreases the longer it is in operation. This belief was reversed in January 2012. In addition, although most experts still denied the vulnerability of nuclear power plants to earthquakes, fewer did so in January 2012 than had been the case prior to that. Despite this, the perception gap between Greater Tokyo residents and AESJ members remains wide.

As shown by the top section of Figure 6, the number of Greater Tokyo residents that did not expect a nuclear accident like the one that occurred in Fukushima to happen (63.4\%) far exceeded the number of those who did (25.8\%). A similar yet more striking contrast can be seen between the $72.5 \%$ of AESJ members who did not expect such an accident to happen and the $18.6 \%$ who did.

The bottom section of Figure 6 shows the results of surveys conducted before the Fukushima nuclear accident with respect to a related question (i.e., the likelihood of a radioactive leak from a nuclear power plant involving civilian deaths in the next 100 years). The

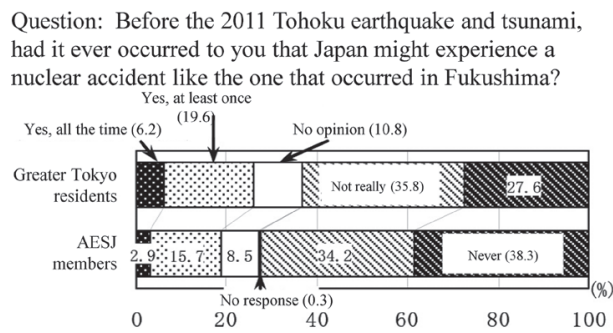

Reference question: Do you think a radioactive substance could leak beyond the premises of a nuclear power plant in Japan within a century and cause civilian deaths?

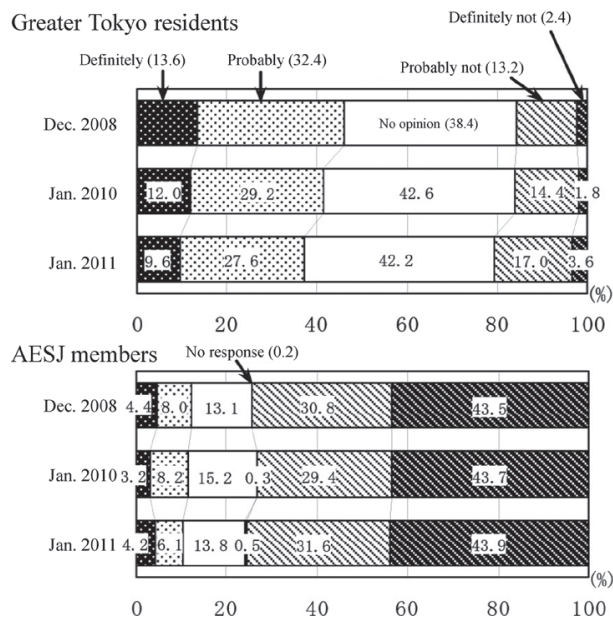

Figure 6 Likelihood of a severe nuclear accident 


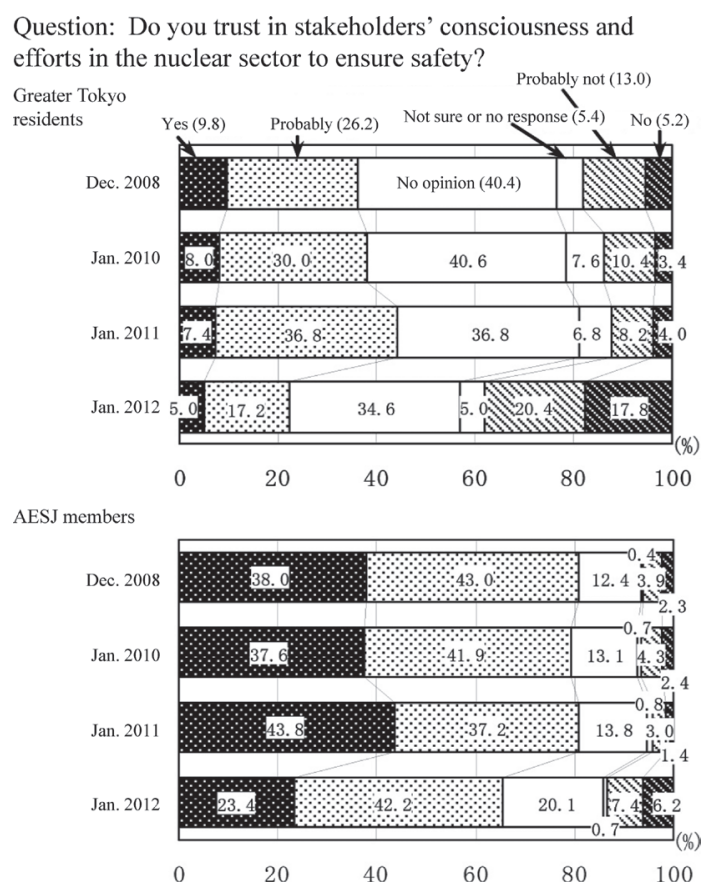

Figure 7 Confidence in consciousness and efforts to ensure nuclear safety

results here show that many Greater Tokyo residents believed that such an accident could occur, and this proportion was much bigger than the proportion of respondents who anticipated the Fukushima nuclear accident. Most likely, the residents could not realistically imagine a nuclear accident occurring before one actually happened in Fukushima, and their answers were based on a vague sense of anxiety. With this no longer being such an abstract concept, people responded with much clearer ideas in January 2012 after having experienced the Fukushima nuclear accident. In other words, the accident had a much greater impact on people's views than the vague possibilities that they had imagined earlier, which presumably explains why a large share of the respondents in January 2012 responded that they had never imagined such an accident could happen.

Similarly, many AESJ members responded that they had not anticipated the Fukushima nuclear accident. Indeed, the accident caught both target groups by surprise.

Figure 7 shows the extent to which both target groups trusted in stakeholders' consciousness and efforts in the nuclear sector to ensure safety. The survey conducted in January 2012 registered a decline in the proportion of Greater Tokyo residents who trusted the stakeholders, and this was combined with a considerable increase in the number of respondents who did not trust them. The gradual increase in public confidence that had been noted in previous surveys was abruptly reversed. Although the majority of AESJ members still maintained their trust even after the accident, the share declined.

\section{Summary}

The findings can be summarized as follows. The Fukushima nuclear accident sparked greater interest in nuclear energy among Greater Tokyo residents. They evidently became concerned about nuclear power, and this increased anxiety fed their mistrust of the nuclear 
industry.

Perceptions among AESJ members remained largely unchanged before and after the accident. Consequently, the perception gap between AESJ members and Greater Tokyo residents has widened somewhat. Nonetheless, AESJ members are also becoming uneasy about nuclear power, less confident about the nuclear industry, and slightly more inclined toward the abandonment of nuclear power. As such, perceptions among AESJ members need to be monitored carefully.

\section{Expected Roles of the AESJ}

So, given the perceptions presented so far, what types of activities should be carried out by the AESJ? As a useful reference for discussing this question, Figure 8 presents the roles that the two target groups expect the AESJ to play.

Greater Tokyo residents expect the AESJ to play a wide range of roles. For them, the top three priorities are to "Deliver accurate data," "Consolidate knowledge on nuclear technologies," and "Evaluate accidents and other such incidents." In contrast, although AESJ members expected the organization to "Disseminate knowledge and raise awareness," "Develop nuclear human resources," and "Transfer nuclear technologies," Greater Tokyo residents felt that these roles were less of a priority. How should these results be interpreted?

Having experienced the Fukushima nuclear accident, Greater Tokyo residents probably expect the AESJ to build up a system aimed at ensuring adequate responses to accidents. At present, they seem to expect the AESJ to play fewer roles in the long term, possibly because their minds have changed since the accident and they see fewer benefits from nuclear power.

The future of nuclear energy is hard to predict as it now depends on a policy choice by the

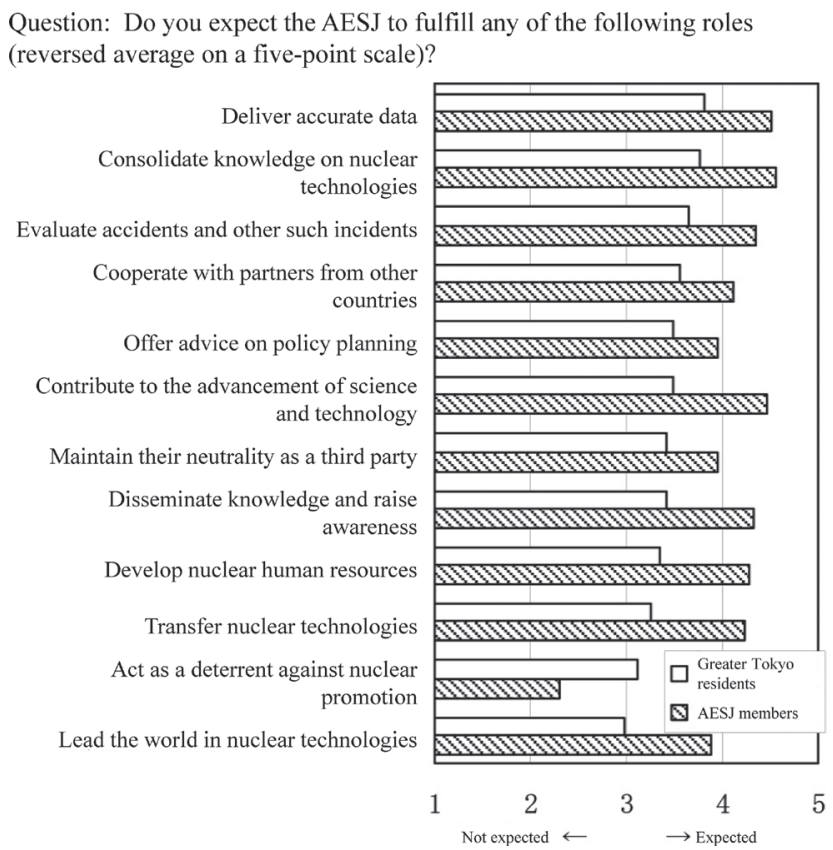

Figure 8 Roles expected of the AESJ (January 2012) 
national government. Whatever the decision, it will take a long time to develop the necessary human resources and maintain adequate nuclear technologies. Certainly, the AESJ must build up its capacity to respond to accidents in line with the expectations of the people of Japan. In addition, the AESJ should probably look to the long term and clarify what needs to be done now, while continuously delivering appropriate information to the Japanese people about the role that it plays.

This commentary is based on studies that the Japan Nuclear Energy Safety Organization commissioned from fiscal 2005 to 2011 conducted by the special committee of the AESJ with the aim of developing and updating a database on media coverage and public opinion with respect to nuclear energy. The data obtained from these studies, including one on perceptions of nuclear safety regulations, have been published by the Social and Environmental Division on the AESJ website. To clarify any issues, please visit the website or contact the author (kimura@nuclear.jp).

On a final note, the author would like to express his gratitude to Mr. Shoji Tsuchida (Kansai University), Mr. Yoshihiko Shinoda (Wakasa Wan Energy Research Center), and the committee members for their generous support in designing and implementing these studies. He would also like to extend his appreciation to the many people and AESJ members who kindly responded to the surveys.

\section{References}

1) Hiroshi Shimooka: Process of Public Attitudes toward Nuclear Power Generation [in Japanese], Journal of the Atomic Energy Society of Japan, 35 (2), 115, 1993.

2) Atomic Energy Society of Japan, Report on the Study of Perceptions of Nuclear Safety Regulations Commissioned by the Japan Nuclear Energy Safety Organization in FY2011 [in Japanese], 2004. 